\title{
Carpel tunnel syndrome: A link with vitamin D and calcium
}

\author{
KHALID KHALEEL ABDUL-RAZZAK ${ }^{1}$ and RAID MOHAMMED KOFAHI ${ }^{2}$ \\ ${ }^{1}$ Department of Clinical Pharmacy, Faculty of Pharmacy; ${ }^{2}$ Department of Neuroscience, Faculty of Medicine, \\ Jordan University of Science and Technology, Irbid-22110, Jordan
}

Received February 22, 2020; Accepted May 20, 2020

DOI: $10.3892 /$ br.2020.1322

\begin{abstract}
Carpal tunnel syndrome (CTS) and vitamin D deficiency are two conditions that cause chronic pain and are thus associated with psychological issues as well. The aim of the present study was to evaluate vitamin D levels, daily calcium intake, musculoskeletal pain and psychological symptoms in patients with CTS. The study included 48 patients with CTS and age-sex matched controls. Serum vitamin D levels were measured, and psychological symptoms were assessed using a Hospital Anxiety and Depression Scale. A Pain DETECT questionnaire was used to assess musculoskeletal pain (MSP) sites and severity. The results showed that vitamin D deficiency was considerably more prevalent in patients with CTS $(95.8 \%)$ compared with controls $(22.9 \%)$. Clinical anxiety (35.4 vs. $6.3 \%)$ and clinical depression (29.2 vs. $4.2 \%)$ were also more common in patients with CTS compared with controls. All the patients with CTS exhibited MSP, whereas none of the controls reported any MSP. Anxiety was significantly and inversely associated with vitamin $D$ levels $\left(r^{2}=-0.482\right.$; $\mathrm{P}<0.01)$, total daily calcium intake $\left(\mathrm{r}^{2}=-0.294: \mathrm{P}<0.05\right)$, and positively associated with body mass index (BMI; $\mathrm{r}^{2}=0.200$; $\mathrm{P} \leq 0.05)$ and depression $\left(\mathrm{r}^{2}=0.587 ; \mathrm{P}<0.01\right)$. Depression was significantly and inversely associated with vitamin $\mathrm{D}$ levels $\left(r^{2}=-0.269 ; P<0.01\right)$ and total daily calcium intake $\left(r^{2}=-0.236\right.$; $\mathrm{P}<0.05)$. Logistic regression analysis showed that with every unit increase in serum vitamin D levels, the odds of CTS were decreased $1.22 x$. While a one-unit increase in anxiety total score was associated with a $14 \%$ increase in the odds of having CTS after adjusting for different confounders. In conclusion, vitamin D deficiency, MSP and psychological symptoms are
\end{abstract}

Correspondence to: Professor Khalid Khaleel Abdul-Razzak, Department of Clinical Pharmacy, Faculty of Pharmacy, Jordan University of Science and Technology, P.O. Box 3030, Irbid-22110, Jordan

E-mail: kkalani@just.edu.jo

Dr Raid Mohammed Kofahi, Department of Neuroscience, Faculty of Medicine, Jordan University of Science and Technology, P.O. Box 3030, Irbid-22110, Jordan

E-mail: raidkofahi@gmail.com

Key words: carpel tunnel syndrome, neuropathy, anxiety, vitamin D, calcium, musculoskeletal pain common in patients with CTS. Serum vitamin D levels and anxiety were significant independent predictors of CTS. Based on the results of the present study, it was shown that housewives had an equivalent chance of suffering from CTS morbidity as other high-risk professions. Further studies are required to confirm if vitamin D supplementation could prevent the onset of CTS.

\section{Introduction}

Carpal tunnel syndrome (CTS) is one of the most common peripheral neuropathies of the upper extremities which results in significant functional disability (1). It is more common between the ages of 30 and 50 years, affects females more often than males and its occurrence is usually bilateral (2).

CTS is a condition caused by compression of the median nerve at the wrist, which runs from the forearm into the palm. The compression causes pain, numbness, tingling in the fingers or hands, particularly the thumb, index and middle fingers in addition to the loss of sensation in the fingers and weakness in the hands (1).

The exact cause and pathogenesis of CTS are unclear. The risks of developing CTS include performing repetitive work tasks, forceful angular hand movements, the use of vibrating tools (3), diabetes mellitus, rheumatoid arthritis, hypothyroidism, obesity and pregnancy (2).

CTS and vitamin D deficiency are two distinct conditions that can cause chronic pain. Several studies have investigated the association between CTS and vitamin D status. The results of these studies suggested that low vitamin D levels are associated with CTS (4-6). Vitamin D is the most commonly observed single most deficient vitamin in different populations, including in areas of the world that receive sufficient sunlight, such as Jordan (7). Vitamin D has also been shown to exert a multitude of effects on various systems, including neuroprotection, anti-inflammatory and anti-proliferative actions by regulating the transcription of vitamin D-responsive genes (8).

CTS and musculoskeletal disorders are reported to be common amongst certain occupational industries, such as those who tools which vibrate (9). Additionally, psychological symptoms are found to be higher in patients with CTS $(10,11)$ and other neuropathic conditions which result in pain (12). However, the precipitating etiology underlying the psychological symptoms is still not well understood (12). Musculoskeletal pain (MSP), weakness, psychological symptoms and neuropathy were found to be accompanied by vitamin $\mathrm{D}$ 
deficiency (13-16). In addition to low serum vitamin D levels, low daily calcium intake was also found to be associated with psychological symptoms in patients with MSP (13), psychiatric outpatients (14), patients with none-cardiac chest pain (17) and patients with an overactive bladder (18). Therefore, the present study aimed to evaluate vitamin D levels, daily calcium intake, MSP and psychological symptoms in patients with CTS.

\section{Materials and methods}

Study population. Patients were recruited from the outpatient clinics of Neurology at King Abdulla University Hospital (KAUH), the main tertiary teaching hospital in the north of Jordan, between December 2015 and June 2016.

Patients were confirmed to have CTS clinically by neurologists and by nerve conduction study (NCS) or CTS group. All tests were performed in the same room, using the NCS system (CADWELL Industries Inc.). The CTS group was compared with an equivalent number of healthy volunteers without any complaints of pain or other issues in the upper limbs, no MSP or fatigue (control) (14). Healthy volunteers were recruited included both males and females who visited different clinics for checkups or as accompanying persons at the university campus of Jordan University of Science and Technology.

The research was performed in accordance with the Declaration of Helsinki (19) and was approved by the Institutional Review Board Committee of Jordan University of Science and Technology. Written informed consent was obtained from all participants. Any history of severe trauma to the wrist, diabetes, thyroid disorders, connective disorders and those who were on vitamin D supplements for the past two months or did not have detectable levels of vitamin $\mathrm{D}$ in the serum were excluded from the study. Additionally, all patients answered a self-guided questionnaire, which contained socio-demographic information.

Data were collected from 48 patients $(8$ males and 40 females), mean age $48.55 \pm 8.3$ (age range, 22-60 years) confirmed to have CTS by NCS or CTS group. In addition, 48 sex-matched healthy subjects aged between 22 and 59 years mean age $42.33 \pm 8.3$ (mean age did not differ significantly from the CTS group, $\mathrm{P}=0.853$ ) were used as the comparison group.

Assessment of MSP. Localization and severity of MSP were determined using two questions from the Pain DETECT questionnaire $(14,15,20)$. The first question asked participants to locate sites of usual pain by marking the area of pain on an illustration of the human body. The second question asked participants to indicate average pain intensity over the last month using a scale from $0-10$ ( 0 , no pain and 10 , maximum pain). Also, the patients answered questions about the frequency of their pain (daily, 4-6 times/week, 2-3 times/week) and duration $\leq 3$ months or $>3$ months. Participants were also asked if they experienced fatigue.

Assessment of psychological symptoms. The Hospital Anxiety and Depression Scale (HADS) were used to assess self-reported symptoms of anxiety and depression for the patients as well as the control. The HADS is a reliable and potentially valid measure for detecting depression and anxiety disorders in both somatic, psychiatric and primary care patients in the general population (21).
According to the total HADS score of the study, subjects were divided into three groups: Total score of 0-7, normal; 8-10, borderline abnormal; and 11-21, abnormal, clinical or a case for either anxiety or depression. A total score for anxiety and depression was calculated by adding together all the values.

Assessment of daily calcium intake. Calcium, an essential mineral in the bone is primarily found in dairy products (22-24). Therefore, milk and milk products are the major sources of dietary calcium. Dietary calcium may also be obtained from non-dairy products, such as nuts, seeds, broccoli and sardines with bones (22). Participants answered questions regarding their daily intake and type of dairy product intake. Daily intake of dairy products, such as milk, yogurt, cheddar cheese, cream cheese and labneh (a soft cream cheese made by the removal of whey from yogurt through a cheesecloth) was stratified as none, single, two, three or more dairy servings per day; where 1 serving was defined as 1 cup of milk or yogurt (300 mg calcium), 2 full tablespoons of labneh (100 mg calcium), 1-ounce of cheese (162 mg calcium) or cream cheese (20 mg calcium) $(13,14,17,18)$.

Laboratory analysis. Non-fasting venous blood samples were drawn for analyses of serum 25-hydroxyvitamin D (25-OHD) levels. Serum 25-OHD levels were determined using a chemiluminescent assay on a Roche Modular E170 Analyzer (Roche Diagnostics). Vitamin D status was divided into four diagnostic categories according to serum $25(\mathrm{OH}) \mathrm{D}$ levels as follows: Vitamin D sufficiency ( $\geq 30 \mathrm{ng} / \mathrm{ml}$ ), vitamin D insufficiency $(20-<30 \mathrm{ng} / \mathrm{ml})$, vitamin D deficiency $(10-<20 \mathrm{ng} / \mathrm{ml})$, and severe vitamin D deficiency $(<10 \mathrm{ng} / \mathrm{ml})$. Vitamin D measurements were performed at the KAUH Laboratory.

Statistical analysis. Data were analyzed using SPSS version 21.0 (IBM, Corp.). Data are presented as frequencies or the mean \pm standard deviation, as appropriate. An independent samples t-test (unpaired) or Mann-Whitney U test were used as appropriate for comparisons between two groups. Spearman's rank correlation coefficient analysis was used to assess the correlation between psychological symptoms and selected parameters with non-normal data. A $\chi^{2}$ test was performed to determine the differences between categorical variables, and to investigate the association between psychological symptoms and categorical variables of interest. Binary logistic regression analysis was used to determine variables predictive of CTS. $\mathrm{P}<0.05$ was considered to indicate a statistically significant difference.

\section{Results}

Patient characteristics. Out of the 48 patients with CTS, $22.9 \%$ $(n=11)$ had positive CTS in the right hand, $12.5 \%(n=6)$ in the left hand, and $66.7 \%(n=31)$ of the patients had bilateral positive CST. Females represented $83.3 \%(n=40)$ of the CTS group and $75 \%(n=36)$ were married. The BMI was significantly different between patients with CTS and the control group, $(\mathrm{P}=0.009)$. The analysis revealed that $85.4 \%(\mathrm{n}=41)$ of the CTS group were either overweight or obese, whereas $66.7 \%$, $\mathrm{n}=32$ of the controls were overweight or obese, (Table I). Self-reported fatigue was reported by $72.9 \%,(n=35)$ of the CTS group compared with $0 \%$ of individuals in the control. 
Table I. Clinicopathological characteristics of the patients.

\begin{tabular}{|c|c|c|c|}
\hline Variables & Case, n (\%) & Control, n (\%) & P-value \\
\hline Age, years & & & 0.853 \\
\hline$<45$ & $30(62.5)$ & $30(62.5)$ & \\
\hline$\geq 45$ & $18(37.5)$ & $18(37.5)$ & \\
\hline Mean \pm SD & $43.57 \pm 8.3$ & $42.33 \pm 8.3$ & 0.69 \\
\hline Sex & & & 1 \\
\hline Male & $8(16.7)$ & $8(16.7)$ & \\
\hline Female & $40(83.3)$ & $40(83.3)$ & \\
\hline Marital status & & & $<0.06$ \\
\hline Single & $12(25)$ & $4(8.3)$ & \\
\hline Married & $36(75)$ & $44(91.7)$ & \\
\hline Body mass index, $\mathrm{kg} / \mathrm{m}^{2}$ & & & $0.009^{\mathrm{a}}$ \\
\hline$<25$ & $7(14.6)$ & $16(33.3)$ & \\
\hline $25-29.9$ & $19(39.6)$ & $23(47.9)$ & \\
\hline$\geq 30$ & $22(45.8)$ & $9(18.8)$ & \\
\hline Mean \pm SD & $31.12 \pm 6.9$ & $27.1 \pm 3.6$ & $0.001^{\mathrm{a}}$ \\
\hline Vitamin D (ng/ml) & & & $<0.001^{\mathrm{b}}$ \\
\hline$\geq 30$ & $1(2.1)$ & $29(60.4)$ & \\
\hline $20-<30$ & $1(2.1)$ & $8(16.7)$ & \\
\hline$<20$ & $46(95.8)$ & $11(22.9)$ & $<0.001^{\mathrm{b}}$ \\
\hline Total calcium intake, mg/day ${ }^{\mathrm{c}}$ & & & $<0.001^{\mathrm{b}}$ \\
\hline$<321.337$ & $22(45.8)$ & $10(20.8)$ & \\
\hline $321.337-<628.22$ & $19(39.6)$ & $13(27.1)$ & \\
\hline$\geq 628.22$ & $7(14.7)$ & $25(52.1)$ & \\
\hline HADS-anxiety & & & $<0.001^{\mathrm{b}}$ \\
\hline Normal & $19(39.6)$ & $43(89.6)$ & \\
\hline Borderline & $12(25)$ & $2(4.2)$ & \\
\hline Abnormal & $17(35.4)$ & $3(6.3)$ & \\
\hline Mean \pm SD & $9.3 \pm 3.6$ & $4.3 \pm 3.5$ & \\
\hline HADS-depression & & & $<0.001^{\mathrm{b}}$ \\
\hline Normal & $17(35.4)$ & $34(70.8)$ & \\
\hline Borderline & $17(35.4)$ & $12(25)$ & \\
\hline Abnormal & $14(29.2)$ & $2(4.2)$ & \\
\hline Mean $\pm \mathrm{SD}$ & $8.4 \pm 4.1$ & $5.4 \pm 3.1$ & $<0.001^{\mathrm{b}}$ \\
\hline
\end{tabular}

${ }^{\mathrm{a}} \mathrm{P}<0.01,{ }^{\mathrm{b}} \mathrm{P}<0.001$. ${ }^{\mathrm{T}}$ Total daily calcium intake dairy + supplement. HADS, Hospital Anxiety and Depression Scale; SD, standard deviation.

All individuals in the CTS group exhibited MSP, $89.6 \%$ $(\mathrm{n}=43)$ of them had chronic pain ( $>3$ months duration), and $70.8 \%(n=34)$ experienced pain for $>1$ year. The CTS group reported a variety of factors that increased pain. The most exacerbating factor was kitchen work $(72.9 \%)$, followed by sleeping $(68.8 \%)$, carrying a handbag $(68.8 \%)$, moving/walking $(50 \%)$ and washing their hair (39.6\%). The average pain intensity for patients with CT was $6.33 \pm 1.74$ compared with 0 for the controls.

Factors that exacerbated pain with respect to sex were not statically significant with the exception of kitchen work. Pain was significantly exacerbated by kitchen work in females (85.0\%, $\mathrm{n}=34)$ compared with males $(12.5 \%, \mathrm{n}=1), \mathrm{P}<0.001$.

Occupational types for patients with CTS were as follows: $66.66 \%(n=32)$ were housewives, $8.32 \%(n=4)$ were manual workers (farmer, chief, carpenter and driver), $6.25 \%(n=3)$ were retired, $4.16 \%(n=2)$ were unemployed, 1 patient was a secretary, $2.08 \%(n=2)$ and the remaining patients were in other occupations, $12.5 \%(n=6)$. Occupational types of the control group was $18.75 \%$ academics $(n=9)$ [professors $(n=6)$, lecturers $(n=2)$ and student $(n=1)]$, laboratory technician $16.66 \%(n=8)$, university laboratory administrator $12.5 \%$ $(n=6)$, office employee $39.58 \%(n=19)$ [office assistant $(n=16)$ and secretary $(n=3)]$ and others $12.48 \%(n=6)$ (Table II).

Biochemical parameters among the study population. There were significant differences in vitamin D levels between the patients with CTS and the controls $(9.53 \pm 7.3$ and $31.65 \pm 14.4$, respectively; $\mathrm{P} \leq 0.001)$. Vitamin $\mathrm{D}$ deficiency $(<20 \mathrm{ng} / \mathrm{ml})$ was 
Table II. Job description of the cohort.

\begin{tabular}{lcc}
\hline Type of job & Case, $\mathrm{n}(\%)$ & Control, $\mathrm{n}(\%)$ \\
\hline Housewife & $32(66.66)$ & 0 \\
Retired & $3(6.25)$ & 0 \\
Teacher & $2(4.16)$ & $2(4.16)$ \\
Driver & $2(4.16)$ & 0 \\
Manual worker & $2(4.16)$ & $1(2.08)$ \\
Office worker & $2(4.16)$ & $16(33.33)$ \\
Nurse & $2(4.16)$ & $1(2.08)$ \\
Secretary & $1(2.08)$ & $3(6.25)$ \\
Jobless & $2(4.16)$ & 0 \\
Academic & 0 & $9(18.75)$ \\
Laboratory technician & 0 & $8(16.66)$ \\
Laboratory administrator & 0 & $6(12.5)$ \\
Research assistant & 0 & $2(4.16)$ \\
\hline
\end{tabular}

observed in $95.8 \%(n=46)$ of the CTS group compared with $22.9 \%(n=11)$ of the controls. Only $2.1 \%(n=1)$ of the CTS group had a normal level of vitamin D ( $\geq 30 \mathrm{ng} / \mathrm{ml})$ compared with $60.4 \%(n=29)$ of the control (Table I).

No clinical parameters (demographics, psychological symptoms, number of pain sites, average pain severity and all other measured parameters) in the CTS patients with respect to sex were statistically significant.

Vitamin D levels amongst the CTS group (male, $11.01 \pm 6.7 \mathrm{ng} / \mathrm{ml}$; female, $9.04 \pm 7.7 \mathrm{ng} / \mathrm{ml} ; \mathrm{P}=0.38)$, and amongst females $<45$ and $\geq 45$ years of age $(9.75 \pm 8.3$ and $9.3 \pm 6.3$, $\mathrm{P}=0.834$, respectively) did not differ significantly.

Concerning total calcium intake ( $\mathrm{mg} / \mathrm{day})$, the analysis showed that the median daily calcium intake was significantly lower in the CTS group compared with the controls (337.428, range, 156.40-549.470; 639.400, range, 353-780; respectively; $\mathrm{P}<0.001)$.

In the CTS group, $45.8 \%(n=22)$ of the participants consumed $<300 \mathrm{mg} /$ day calcium compared with $16.5 \%(\mathrm{n}=8)$ in the control group, which is $\sim<1 / 4$ the Recommended Dietary Allowance (1,000-1,300 mg depending on age group) (25).

Psychological symptoms. The CTS group had notably worse psychological symptoms compared with the controls. Clinical anxiety and clinical depression (HADS score, $\geq 11$ ) were reported by 35.4 and $29.2 \%$ of participants in the CTS group, respectively, whereas $4.3 \%$ of controls had clinical anxiety and $2.0 \%$ of had clinical depression (Table I).

Correlation between psychological symptoms and the assessed variables. Psychological symptoms were significantly and inversely correlated with vitamin D levels and total daily calcium intake, and positively correlated with BMI. Depression was significantly and positively correlated with anxiety. The values of Spearman's correlation coefficient analysis reflect a strong correlation $(>0.25)$ with the exception of BMI (Table III).

Logistic regression analysis for predictors of CTS among the study population. As there was only one patient with CTS+
Table III. Spearman's rank correlation between psychological symptoms and selected parameters.

\begin{tabular}{lcc}
\hline Variables & $\begin{array}{c}\text { HADS- } \\
\text { anxiety, } \mathrm{r}^{2}\end{array}$ & $\begin{array}{c}\text { HADS- } \\
\text { depression, } \mathrm{r}^{2}\end{array}$ \\
\hline Age, years & -0.1 & 0.006 \\
Body mass index, $\mathrm{kg} / \mathrm{m}^{2}$ & $0.200^{\mathrm{a}}$ & 0.141 \\
Serum vitamin D, $\mathrm{ng} / \mathrm{ml}$ & $-0.482^{\mathrm{b}}$ & $-0.296^{\mathrm{b}}$ \\
Total calcium intake, $\mathrm{mg} /$ day $^{\mathrm{c}}$ & $-0.294^{\mathrm{a}}$ & $-0.236^{\mathrm{a}}$ \\
HADS-anxiety & 1.00 & $0.587^{\mathrm{b}}$ \\
\hline
\end{tabular}

A 2-tailed Spearman correlation coefficient significant at a threshold of ${ }^{\mathrm{a}} \mathrm{P}<0.05$ or ${ }^{\mathrm{b}} \mathrm{P}<0.01$. ${ }^{\mathrm{c}}$ Total daily calcium intake dairy + supplement. HADS, Hospital Anxiety and Depression Scale.

who had normal vitamin D levels and one patient with CTS+ who had insufficient vitamin levels, continuous logistic regression analysis rather than categorical analysis was used to determine variables predictive of CTS.

Logistic regression revealed that with every unit increase in serum vitamin D levels, the odds of having CTS was decreased by $1.22 \mathrm{x}$. While a one-unit increase in anxiety total score was associated with a $14 \%$ increase in the odds of having CTS after adjusting for different confounders (Table IV).

Association between NCS severity and selected parameters. Based on the NCS rating for CTS symptom severity (mild, moderate or severe), none of the measured parameters were associated with CTS severity in either or both hands, with the exception of MSP frequency. Pain frequency (daily, 4-6 times/week, 2-3 times/week) was significantly associated with CTS severity for the right hand only $(\mathrm{P}=0.012)$.

\section{Discussion}

In the present study, the relationship between serum vitamin D levels with MSP, psychological symptoms and daily dietary calcium intake in patients with CTS were evaluated and compared with healthy controls.

The most notable finding of the present study was the presence of a high prevalence of vitamin D deficiency, MSP, fatigue, clinical anxiety and clinical depression amongst Jordanian patients with CTS compared with healthy individuals. Additionally, serum vitamin D levels and HADS-anxiety total score were independent predictors of CTS. The majority of the CT patients were females and were housewives.

Regarding the association between vitamin D deficiency and CTS, the results are in agreement with previous studies. CTS patients had significantly lower vitamin D levels compared with the controls. This observation was in agreement with previously published studies from Tanik et al (4), Nageeb et al (5) and Gürsoy et al (26). In contrast, Lee et al (27) showed there was no difference in vitamin D levels between the patients with CTS and the controls.

There is a growing body of evidence demonstrating that vitamin $\mathrm{D}$ is neuroprotective. The administration of vitamin $\mathrm{D}$ or its metabolites has been shown to reduce neurological 
Table IV. Logistical regression analysis for predictors of Carpal tunnel syndrome.

\begin{tabular}{lcc}
\hline Variables & Odds ratio $(95 \%$ confidence interval) & P-value \\
\hline Serum vitamin D, ng/ml & $0.835(0.763-0.915)$ & $<0.001^{\mathrm{b}}$ \\
Body mass index, $\mathrm{kg} / \mathrm{m}^{2}$ & $1.144(0.971-1.349)$ & 0.107 \\
HADS-anxiety & $1.436(1.116-1.847)$ & $0.005^{\mathrm{a}}$ \\
HADS-depression & $0.982(0.997-1.240)$ & 0.876 \\
Total calcium intake, mg/day & $0.999(0.997-1.002)$ & 0.581
\end{tabular}

${ }^{\mathrm{a}} \mathrm{P} \leq 0.05$ or ${ }^{\mathrm{b}} \mathrm{P}<0.001$. $^{\mathrm{c}}$ Total daily calcium intake dairy + supplement. HADS, Hospital Anxiety and Depression Scale.

injury and/or neurotoxicity in a variety of animal systems by several mechanisms, including protection of neurons against oxidative stress through its antioxidant and anti-inflammatory properties $(27,28)$. Additionally, vitamin D can regulate intraneuronal calcium homeostasis and $\beta$-amyloid deposition (28). Neuroinflammation is one of the most important processes involved in the pathogenesis of neurodegenerative diseases, such as Alzheimer's disease, Parkinson's disease and Multiple Sclerosis.

In the last decade, there has been an increase in the interest in the roles of vitamin D in peripheral nerve functions. Diabetes mellitus is a clinical condition that contributes several neuropathies. Shehab et al (29) showed that diabetic peripheral neuropathy was significantly associated with vitamin D deficiency, whereas Celikbilek et al (30) reported that diabetic patients with neuropathy had lower levels of vitamin D compared with those without neuropathies.

In the present study, $95.8 \%$ of patients with CTS had vitamin D deficiency compared with $22.9 \%$ of the controls. Also, regression analysis showed that vitamin D deficiency is one of the independent risk factors of CTS. Thus, our study suggests that CTS symptoms may be triggered by low vitamin D levels.

In addition to the presence of a high prevalence of vitamin D deficiency, all CTS patients had MSP, and the majority of them experienced fatigue. MSP that is associated with vitamin D deficiency is explained by the presence of low bone density and osteomalacia in adults (16), heightened central sensitivity upon mechanical stimulation (31) and the growth of muscle fibers (32). Intestinal calcium absorption is significantly reduced to $10-15 \%$ when children and adults are vitamin D deficient (33).

The association between neuropathic pain and psychological symptoms is well recognized $(34,35)$; however, the precipitating pathology between these symptoms remains unclear. Tekeoglu et al (10) found that the majority of patients in the CTS group had higher symptoms of depression and anxiety, compared with the control group, which significantly improved at 3 months after carpal tunnel release (36).

In the present study, in addition to MSP, there was a high prevalence of clinical anxiety and clinical depression among patients with CTS. Additionally, serum vitamin D levels and daily calcium intake were significantly inversely associated with anxiety/depression symptoms. HADS-anxiety was one of the independent risk factors associated with CTS.

In agreement with the results of the present study, a high prevalence between vitamin $\mathrm{D}$ deficiency and psychological symptoms among patients with MSP has been previously reported $(13,37)$. These findings may have implications in understanding the bidirectional association between the psychological symptoms and MSP among patients with CTS. This finding also raises the question about the relation between CTS and MSP, and if vitamin D and calcium supplementation can be used to treat CTS similar to patients with MSP (13).

CTS is suggested to be provoked by repetitive movements that put stress on the arm or wrist, or specific wrist postures, but may also not be a work-related problem (38). Interestingly, $66.66 \%$ of our females with CTS were housewives, relatively consistent with previously published articles (39-41). The high incidence of CTS in housewives can be attributed to routine domestic home duties that involve repetitive movements (42).

In Jordan, wrapped grape leaves (grape leaves stuffed with rice and herbs) and stuffed zucchini which requires hollowing out zucchini using a vegetable corer, are common recipes of Jordanian cuisine that require repetitive hand movement of both hands which involves prolonged taxing hand-wrist activities, and highly repetitive wrist flexion/extension.

The association between parameters, such as sex, increased age, a high BMI and CTS have been reported in numerous studies. CTS patients have higher BMI values compared with controls $(5,43,44)$, consistent with findings from the present study. Some $45.8 \%$ of patients with CTS were obese compared with $18.8 \%$ of the controls. This effect may be due to the fat deposition in the carpel tunnel that results in compression of the median nerve (43). Additionally, CTS was more common in women $>50$ years (45). The results of the present study were consistent with previous findings, $83.3 \%$ of the CTS patients were females and $75 \%$ were between $30-50$ years of age. The sex differences were attributed partially to pregnancy, breastfeeding and first menopausal years (46).

In the present study, although patients with CTS had a significantly higher BMI and lower vitamin D levels compared with controls, there were no significant differences between males and females in the mean vitamin D levels amongst the CTS group, or between females aged $<45$ and $\geq 45$ years. In both cases, females had significantly lower vitamin D levels compared with controls. In contrast with these results, Lee et al (27) found women with CTS >50 years had significantly lower vitamin D levels than the age-matched healthy control women. Tanik et al (4) also reported that women with CTS $<40$ years had significantly lower levels of vitamin D compared with the sex-matched controls. 
Overall, a high incidence of vitamin D deficiency, MSP and psychological symptoms was observed. Furthermore, there was a significant negative association between anxiety/depression symptoms, vitamin D levels, and total daily calcium intake observed among patients with CTS. There was a positive association between anxiety symptoms and depression symptoms. CTS was more common in females than males, and the majority of the females were housewives. Serum vitamin D levels and HADS-anxiety total score were independent predictors of CTS.

The strengths of the present study come from its design, and the method of CTS assessment. However, the small sample size, and the fact that all the recruited participants were from Jordan are limitations of the present study. In the future, collaborative studies between institutes from different countries are required to obtain a larger and more ethnically diverse cohort for evaluation.

In conclusion, the findings of the present study demonstrated that vitamin D deficiency, MSP, and anxiety and depression are common problems in patients with CTS. Low vitamin D levels and HADS-Anxiety were significant independent predictors of CTS. Logistic regression analysis showed with every with unit increase in serum vitamin D levels, the odds of having CTS were decreased by $1.22 x$. While a one-unit increase in anxiety total score was associated with a $14 \%$ increase in the odds of having CTS after adjusting for different confounders. Housewives had an equivalent chance of suffering from CTS morbidity as other high-risk professions. Further studies are required to confirm if vitamin $\mathrm{D}$ supplementation may prevent the onset of CTS.

\section{Acknowledgements}

Not applicable.

\section{Funding}

The research was supported by funds from a Deanship of Research, Jordan University of Science and Technology (Irbid, Jordan) (grant no. 225/2014).

\section{Availability of data and materials}

The datasets used and/or analyzed during the present study are available from the corresponding author on reasonable request.

\section{Authors' contributions}

KKAR conceived and designed the study and drafted the manuscript. RMK performed the clinical assessment of patients, interpreted the patients' data and revised the manuscript critically for important intellectual content. Both authors read and approved the final manuscript.

\section{Ethics approval and consent to participate}

The Institutional Review Board Committee at Jordan University of Science and Technology (Irbid, Jordan) approved the present study (approval no. 19/78/2014). Written informed consent was obtained from all participants after discussing the purpose of the study and the procedure.

\section{Patient consent for publication}

Not applicable.

\section{Competing interests}

The authors declare that they have no competing interests.

\section{References}

1. Ghasemi-Rad M, Nosair E, Vegh A, Mohammadi A, Akkad A, Lesha E, Mohammadi MH, Sayed D, Davarian A, Maleki-Miyandoab T and Hasan A: A handy review of carpal tunnel syndrome: From anatomy to diagnosis and treatment. World J Radiol 6: 284-300, 2014.

2. Aroori S and Spence RA: Carpal tunnel syndrome. Ulster Med J 77: 6-17, 2008.

3. Newington L, Harris EC and Walker-Bone K: Carpal tunnel syndrome and work. Best Pract Res Clin Rheumatol 29: 440-453, 2015.

4. Tanik N, Balbaloğlu Ö, Ucar M, Sarp U, Atalay T, Çelikbilek A, Göçmen AY and Inan LE: Does vitamin D deficiency trigger carpal tunnel syndrome? J Back Musculoskelet Rehabil 29: 835-839, 2016.

5. Nageeb RS, Shehta N, Nageeb GS and Omran AA: Body mass index and vitamin $\mathrm{D}$ level in carpal tunnel syndrome patients. Egypt J Neurol Psychiatr Neurosurg 54: 14, 2018.

6. Demiryurek BE and Gundogdu AA: The effect of vitamin D levels on pain in carpal tunnel syndrome. Orthop Traumatol Surg Res 103: 919-922, 2017.

7. Edwards MH, Cole ZA, Harvey NC and Cooper C: The global epidemiology of vitamin D status. J Aging Res Clin Practice 3: 148-158, 2014.

8. Kim K, Gong HS, Kim J and Baek GH: Expression of vitamin D receptor in the subsynovial connective tissue in women with carpal tunnel syndrome. J Hand Surg Eur Vol 43: 290-295, 2018.

9. Bonfiglioli R, Mattioli S, Spagnolo MR and Violante FS: Course of symptoms and median nerve conduction values in workers performing repetitive jobs at risk for carpal tunnel syndrome. Occup Med (Lond) 56: 115-121, 2006.

10. Tekeoglu I, Gulcu E, Sayin R, Besiroglu L and Yazmalar L: Sleep quality, depression and anxiety in carpal tunnel syndrome/Karpal tunel sendromunda uyku kalitesi ile depresyon ve anksiyete bulgulari. Turk J Phys Med Rehab: 102-107, 2008.

11. Jerosch-Herold C, Houghton J, Blake J, Shaikh A, Wilson EC and Shepstone L: Association of psychological distress, quality of life and costs with carpal tunnel syndrome severity: A cross-sectional analysis of the PALMS cohort. BMJ Open 7: e017732, 2017.

12. Sieberg CB, Taras C, Gomaa A, Nickerson C, Wong C, Ward C, Baskozos G, Bennett DLH, Ramirez JD, Themistocleous AC, et al: Neuropathic pain drives anxiety behavior in mice, results consistent with anxiety levels in diabetic neuropathy patients. Pain Rep 3: e651, 2018.

13. Abdul-Razzak KK, Mayyas FA and Al-Farras MI: Vitamin D as potential antidepressant in outpatients with musculoskeletal pain. Int J Clin Pharmacol Ther 56: 400-410, 2018.

14. Abdul-Razzak KK, Almanasrah SO, Obeidat BA and Khasawneh AG: Vitamin D is a potential antidepressant in psychiatric outpatients. Int J Clin Pharmacol Ther 56: 585-596, 2018.

15. Alkhatatbeh MJ, Abdul-Razzak KK, Khasawneh LQ and Saadeh NA: Prevalence of musculoskeletal pain in association with serum 25-hydroxyvitamin D concentrations in patients with type 2 diabetes mellitus. Biomed Rep 8: 571-577, 2018.

16. McCabe PS, Pye SR, Mc Beth J, Lee DM, Tajar A, Bartfai G, Boonen S, Bouillon R, Casanueva F, Finn JD, et al: Low vitamin D and the risk of developing chronic widespread pain: Results from the European male ageing study. BMC Musculoskelet Disord 17: 32, 2016.

17. Alkhatatbeh MJ, Abdul-Razzak KK, Amara NA and Al-Jarrah M: Non-cardiac chest pain and anxiety: A possible link to vitamin D and calcium. J Clin Psychol Med Settings 26: 194-199, 2019.

18. Abdul-Razzak KK, Alshogran OY, Altawalbeh SM, Al-Ghalayini IF, Al-Ghazo MA, Alazab RS, Halalsheh OM and Sahawneh FE: Overactive bladder and associated psychological symptoms: A possible link to vitamin D and calcium. Neurourol Urodyn 38: 1160-1167, 2019. 
19. Goodyear MD, Krleza-Jeric K and Lemmens T: The declaration of Helsinki. BMJ 335: 624-625, 2007.

20. Freynhagen R, Baron R, Gockel U and Tölle TR: painDETECT: A new screening questionnaire to identify neuropathic components in patients with back pain. Curr Med Res Opin 22: 1911-1920, 2006.

21. Axford J, Butt A, Heron C, Hammond J, Morgan J, Alavi A, Bolton $\mathrm{J}$ and Bland $\mathrm{M}$ : Prevalence of anxiety and depression in osteoarthritis: Use of the hospital anxiety and depression scale as a screening tool. Clin Rheumatol 29: 1277-1283, 2010.

22. Rolfes SR, Pinna K and Whitney E: Understanding Normal and Clinical Nutrition. 9th edition. Cengage Learning, 2009.

23. Abdul-Razzak KK, Obeidat BA, Al-Farras MI and Dauod AS: Vitamin D and PTH status among adolescent and young females with severe dysmenorrhea. J Pediatr Adolesc Gynecol 27: 78-82, 2014.

24. Gao X, Wilde PE, Lichtenstein AH and Tucker KL: Meeting adequate intake for dietary calcium without dairy foods in adolescents aged 9 to 18 years (National Health and Nutrition Examination Survey 2001-2002). J Am Diet Assoc 106: 1759-1765, 2006.

25. Lima GA, Lima PD, Barros Mda G, Vardiero LP, Melo EF, Paranhos-Neto Fde P, Madeira M and Farias ML: Calcium intake: Good for the bones but bad for the heart? An analysis of clinical studies. Arch Endocrinol Metab 60: 252-263, 2016.

26. Gürsoy AE, Bilgen HR, Dürüyen H, Altıntaş Ö, Kolukisa M and Asil T: The evaluation of vitamin D levels in patients with carpal tunnel syndrome. Neurol Sci 37: 1055-1061, 2016.

27. Lee SH, Gong HS, Kim DH, Shin HS, Kim KM, Kim J and Baek GH: Evaluation of vitamin D levels in women with carpal tunnel syndrome. J Hand Surg Eur Vol 41: 643-647, 2016.

28. AlJohri R, AlOkail M and Haq SH: Neuroprotective role of vitamin $\mathrm{D}$ in primary neuronal cortical culture. eNeurological Sci 14: 43-48, 2019

29. Shehab D, Al-Jarallah K, Mojiminiyi OA, Al Mohamedy $\mathrm{H}$ and Abdella NA: Does vitamin D deficiency play a role in peripheral neuropathy in type 2 diabetes? Diabet Med 29: 43-49, 2012.

30. Celikbilek A, Gocmen AY, Tanik N, Borekci E, Adam M, Celikbilek M, Suher M and Delibas N: Decreased serum vitamin $\mathrm{D}$ levels are associated with diabetic peripheral neuropathy in a rural area of Turkey. Acta Neurol Belg 115: 47-52, 2015.

31. Shipton EE and Shipton EA: Vitamin D deficiency and pain: Clinical evidence of low levels of vitamin $\mathrm{D}$ and supplementation in chronic pain states. Pain Ther 4: 67-87, 2015.

32. Muir SW and Montero-Odasso M: Effect of vitamin D supplementation on muscle strength, gait and balance in older adults: A systematic review and meta-analysis. J Am Geriatr Soc 59: 2291-2300, 2011
33. Holick MF: Vitamin D: Evolutionary, physiological and health perspectives. Curr Drug Targets 12: 4-18, 2011.

34. Torta R, Ieraci V and Zizzi F: A review of the emotional aspects of neuropathic pain: from comorbidity to co-pathogenesis. Pain Ther 6 (Suppl 1): S11-S17, 2017.

35. Turk DC, Audette J, Levy RM, Mackey SC and Stanos S: Assessment and treatment of psychosocial comorbidities in patients with neuropathic pain. Mayo Clin Proc 85 (3 Suppl): S42-S50, 2010.

36. Shin YH, Yoon JO, Kim YK and Kim JK: Psychological status is associated with symptom severity in patients with carpal tunnel syndrome. J Hand Surg Am 43: 484.e1-484.e8, 2018.

37. Castro M, Quarantini L, Daltro C, Pires-Caldas M, Koenen K, Kraychete D and Oliveira I: Comorbidade de sintomas ansiosos e depressivos em pacientes com dor crônica e o impacto sobre a qualidade de vida. Arch Clin Psychiatry (São Paulo) 38: 126-129, 2011.

38. Werner RA: Evaluation of work-related carpal tunnel syndrome. J Occup Rehabil 16: 207-222, 2006.

39. Chaurasia RN, Kawale SS, Pathak A, Mishra VN and Joshi D: Clinical evaluation and diagnostic utilities of different nerve conduction tests in 100 patients with carpal tunnel syndrome. J Neurosci Rural Pract 8: 575-580, 2017.

40. Mattioli S, Baldasseroni A, Curti S, Cooke RM, Mandes A, Zanardi F, Farioli A, Buiatti E, Campo G and Violante FS: Incidence rates of surgically treated idiopathic carpal tunnel syndrome in blue- and white-collar workers and housewives in Tuscany, Italy. Occup Environ Med 66: 299-304, 2009.

41. Abdalla SF: Neurophysiologic pattern and severity grading scale of carpal tunnel syndrome in sudanese patients. Archiv Med 8: 213, 2017

42. Sala E, Mattioli S, Violante FS and Apostoli P: Risk assessment of biomechanical load for the upper limbs in housework. Med Lav 98: 232-251, 2007 (In Italian).

43. Kouyoumdjian JA, Morita MD, Rocha PR, Miranda RC and Gouveia GM: Body mass index and carpal tunnel syndrome. Arq Neuropsiquiatr 58: 252-256, 2000

44. Komurcu HF, Kilic S and Anlar O: Relationship of age, body mass index, wrist and waist circumferences to carpal tunnel syndrome severity. Neurol Med Chir (Tokyo) 54: 395-400, 2014.

45. Atalay NS, Sarsan A, Akkaya N, Yildiz N and Topuz O: The impact of disease severity in carpal tunnel syndrome on grip strength, pinch strength, fine motor skill and depression. J Phys Ther Sci 23: 115-118, 2011.

46. Nordstrom DL, Vierkant RA, DeStefano F and Layde PM: Risk factors for carpal tunnel syndrome in a general population. Occup Environ Med 54: 734-740, 1997. 